\title{
PREPARATION OF A MODIFIED SUBTILIN SUITABLE FOR THE TREATMENT OF TUBERCULOSIS AND OTHER INFECTIONS IN ANIMALS ${ }^{1,2}$
}

\author{
By A. J. SALLE AND GREGORY J. JANN
}

(From the Department of Bacteriology, University of California, Los Angeles)

Subtilin is an antibiotic extracted from the cells of a particular strain of Bacillus subtilis., 3 It is a low molecular weight substance that dialyzes through collodion membranes, is sensitive to light and alkali, and has the structure of a peptide.

Subtilin is soluble to at least 30 per cent in saltfree acidified solution. The solubility in acid solution is markedly decreased by the presence of salt. In the presence of 0.5 to 1 per cent of sodium chloride the solubility is reduced to approximately 0.5 to 0.2 per cent. The addition of serum to an aqueous solution of subtilin produces a marked precipitation. The antibiotic is probably a basic substance giving water-soluble salts (1).

The antibacterial spectrum of subtilin (2) is similar to that of penicillin. It seems reasonable to postulate that the antibiotic might prove useful in infections caused by penicillin-fast or penicillinresistant organisms. In addition, subtilin is effective against Mycobacterium tuberculosis which is not antagonized by penicillin.

The low solubility of subtilin in salt solutions and in serum is probably a desirable property in the treatment of infections caused by such organisms as the pneumococcus (3), streptococci (4), micrococci (5), the anthrax bacillus (6), etc., in which relatively small doses are required. Precipitation of the antibiotic in the presence of body fluids should slow down its elimination, thus giv-

\footnotetext{
1 Presented at the Second National Symposium on Recent Advances in Antibiotics Research held in Washington, D. C., April 11-12, 1949, under the auspices of the Antibiotics Study Section, National Institutes of Health, Public Health Service, Federal Security Agency.

2 This work was aided by a grant from the Antibiotics Study Section, National Institutes of Health, United States Public Health Service, Bethesda, Maryland.

${ }^{8}$ The culture was originally obtained from Dr. N. R. Smith of the Bureau of Plant Industry, United States Department of Agriculture, Washington, D. C.

4 The subtilin used in these experiments was kindly supplied by the Western Regional Research Laboratory, Albany, California.
}

ing a more prolonged effect. However, for the effective treatment of tuberculosis the antibiotic concentration of the tissues must be maintained at a very high level. Unless the solubility of subtilin in the presence of serum can be increased it will be of limited value in the chemotherapy of tuberculosis.

\section{EXPERIMENTAL}

The solubility of the antibiotic may be improved considerably as follows: 1 . Dissolve $1.5 \mathrm{gm}$. of subtilin in $50 \mathrm{ml}$. of 20 per cent urea in distilled water; 2. dissolve $0.1 \mathrm{gm}$. of pectin in $50 \mathrm{ml}$. of distilled water; 3 . mix 1 . and 2 . and let stand overnight at room temperature for a precipitate to settle out. Centrifugate the mixture and decant the clear supernatant liquid. This clear liquid contains subtilin that is soluble in serum in all proportions and may be administered without any further treatment.

The injection of unmodified subtilin subcutaneously resulted in the formation of very hard nodule-like deposits under the skin. The subtilin was apparently largely precipitated. Sometimes these deposits produced an ulceration of the skin followed by discharge of the insoluble subtilin. Obviously, not many injections could be given. The addition of urea to a solution of subtilin increases its solubility and prevents precipitation of most of the antibiotic in the presence of serum. The pectin precipitates out that portion of the subtilin that is not soluble in the presence of serum. The removal of the precipitate gives a serumsoluble subtilin that does not produce nodule-like deposits when injected subcutaneously but is completely absorbed.

The project on the chemotherapy of tuberculosis has been under way for a period of approximately three years. At least 15 experiments have been completed involving a total of over 700 guinea pigs. The work has involved proper dosage, number of doses daily, route of injection of subtilin, and preparation of subtilin before injection. 
In most experiments a total of $\mathbf{4 8}$ guinea pigs were used weighing approximately $500 \mathrm{gm}$. each. The animals were infected subcutaneously with 0.3 mg. each of Mycobacterium tuberculosis H37Rv grown in Proskauer and Beck's synthetic medium, then divided into four groups. Group 1 animals received subtilin alone; group 2 received streptomycin alone; group 3 received a mixture of subtilin and streptomycin; and group 4 animals served as controls. Treatments were commenced generally the same day that the animals were infected. The antibiotics were injected subcutaneously three times a day at 9 a.m., 3 p.m., and 9 p.m. for 42 consecutive days (six weeks). The results of only the last three experiments are reported here.

Control Guinea Pigs. Animals in this group were inoculated with Mycobacterium tuberculosis

TABLE I

Guinea pigs were infected with M. tuberculosis $H 37 R v$ but not treated (controls)

\begin{tabular}{|c|c|c|c|c|c|c|c|}
\hline Animal & Liver & Lungs & Spleen & Animal & Liver & Lungs & Spleen \\
\hline $\begin{array}{l}\text { A1 } \\
\text { A2 } \\
\text { A3 } \\
\text { A4 } \\
\text { A5 } \\
\text { B1 } \\
\text { B2 } \\
\text { B3 } \\
\text { B4 } \\
\text { B5 } \\
\text { B6 } \\
\text { B7 } \\
\text { B8 }\end{array}$ & $\begin{array}{r}++ \\
0 \\
++ \\
+ \\
+\end{array}$ & $\begin{array}{c}0 \\
0 \\
0 \\
0 \\
++ \\
++ \\
0 \\
+++ \\
+++ \\
+++ \\
0 \\
0 \\
+++\end{array}$ & $\begin{array}{c}t+ \\
+t \\
+t+\end{array}$ & $\begin{array}{l}\text { B9 } \\
\text { B10 } \\
\text { B11 } \\
\text { C1 } \\
\text { C2 } \\
\text { C3 } \\
\text { C4 } \\
\text { C5 } \\
\text { C6 } \\
\text { C7 } \\
\text { C8 } \\
\text { C9 } \\
\text { C10 }\end{array}$ & $\begin{array}{c}+t \\
++ \\
0 \\
0 \\
0 \\
0 \\
0 \\
0 \\
++ \\
0 \\
++ \\
0 \\
++\end{array}$ & & $\begin{array}{c}++ \\
++ \\
0 \\
++ \\
0 \\
0 \\
++ \\
++ \\
0 \\
++ \\
++ \\
+t\end{array}$ \\
\hline
\end{tabular}

$\mathbf{0}=$ No macroscopic lesions

$t=$ Very slight infection

$++=$ More pronounced infection

$+++=$ Heavy infection

H37Rv but not treated. They served as the controls. The results are given in Table I. The method of designation of the degree of infection in this and in subsequent tables is as follows: $0=$ no macroscopic lesions; $+=$ very slight infection; $++=$ more pronounced infection; and $+++=$ heavy infection. With a few exceptions animals in this group showed pronounced to heavy infections in the liver, lungs, or spleen. A large nodule was present at the site of the original infection.

Animals Treated with Streptomycin. Twentysix guinea pigs were treated with 9000 units of streptomycin per day (three injections) over a period of six weeks. With a few doubtful exceptions no macroscopic lesions were noted. Animals
TABLE II

Treatment of guinea pigs with streptomycin 2400 units/day (three injections) for a period of six weeks

\begin{tabular}{|c|c|c|c|c|c|c|c|}
\hline Animal & Liver & Lungs & Spleen & Animal & Liver & Lungs & Spleen \\
\hline $\begin{array}{l}\text { A1 } \\
\text { A2 } \\
\text { A3 } \\
\text { A4 } \\
\text { A5 } \\
\text { B1 } \\
\text { B2 } \\
\text { B3 } \\
\text { B4 } \\
\text { B5 } \\
\text { B6 } \\
\text { B7 } \\
\text { B8 }\end{array}$ & $\begin{array}{c}+ \\
0 \\
0 \\
0 \\
0 \\
0 \\
0 \\
0 \\
+ \\
+ \\
0 \\
+ \\
++\end{array}$ & $\begin{array}{c}0 \\
++ \\
0 \\
+++ \\
0 \\
+++ \\
0 \\
++ \\
+++ \\
0 \\
0 \\
0 \\
++\end{array}$ & $\begin{array}{c}0 \\
++ \\
+ \\
++ \\
0 \\
0 \\
++ \\
0 \\
++ \\
++ \\
0 \\
++ \\
++\end{array}$ & $\begin{array}{l}B 9 \\
B 10 \\
C 1 \\
C 2 \\
C 3 \\
C 4 \\
C 5 \\
C 6 \\
C 7 \\
C 8 \\
C 9 \\
C 10 \\
C 11\end{array}$ & $\begin{array}{c}0 \\
++ \\
0 \\
0 \\
+ \\
0 \\
0 \\
++ \\
0 \\
++ \\
0 \\
+ \\
0\end{array}$ & $\begin{array}{c}0 \\
++ \\
++ \\
0 \\
+++ \\
++ \\
0 \\
++ \\
0 \\
++ \\
0 \\
0 \\
0\end{array}$ & $\begin{array}{c}0 \\
++ \\
++ \\
0 \\
0 \\
++ \\
0 \\
++ \\
++ \\
++ \\
+ \\
0\end{array}$ \\
\hline
\end{tabular}

$0=$ No macroscopic lesions

$t=$ Very slight infection

$++=$ More pronounced infection $+t+=$ Heavy infection

appeared normal except for a small nodule at the site of infection.

On the other hand, a similar number of infected animals treated with 2400 units of streptomycin per day exhibited an entirely different picture. The results are reported in Table II. Five of the animals were macroscopically negative. In the others the antibiotic produced only a suppressive effect. Lesions were present in the liver, lungs, or spleen.

Animals Treated with Subtilin. A group of guinea pigs were treated with $22 \mathrm{mg}$. of subtilin per day (three injections). The results are recorded in Table III. One-half of the animals were treated with a lot of subtilin that exhibited a low tuberculostatic effect; the other half were treated with a quantity of subtilin that showed a high tuberculostatic action. Of the 11 animals in the

TABLE III

Treatment of guinea pigs with subtilin $22 \mathrm{mg} . /$ day (three injections) for a period of six weeks

\begin{tabular}{|c|c|c|c|c|c|c|c|}
\hline \multicolumn{4}{|c|}{ Poor quality of subtilin } & \multicolumn{4}{|c|}{ Good quality of subtilin } \\
\hline Animal & Liver & Lungs & Spleen & Animal & Liver & Lungs & Spleen \\
\hline $\begin{array}{l}\text { B1 } \\
\text { B2 } \\
\text { B3 } \\
\text { B4 } \\
\text { B5 } \\
\text { B6 } \\
\text { B7 } \\
\text { B8 } \\
\text { B9 } \\
\text { B10 } \\
\text { B11 }\end{array}$ & $+{ }^{0}$ & $\begin{array}{c}0 \\
+ \\
+ \\
0 \\
+ \\
+ \\
+\end{array}$ & & $\begin{array}{l}\text { C1 } \\
\text { C2 } \\
\text { C3 } \\
\text { C4 } \\
\text { C5 } \\
\text { C6 } \\
\text { C7 } \\
\text { C8 } \\
\text { C9 } \\
\text { C10 } \\
\text { C11 }\end{array}$ & $\begin{array}{c}\mathbf{0} \\
0 \\
\mathbf{0} \\
\mathbf{0} \\
\mathbf{0} \\
\mathbf{0} \\
\mathbf{0} \\
+\underset{+}{+}+ \\
\mathbf{0} \\
\mathbf{0} \\
\mathbf{0}\end{array}$ & $\begin{array}{c}\mathbf{0} \\
0 \\
+ \\
\mathbf{0} \\
++ \\
\mathbf{0} \\
\mathbf{0} \\
\mathbf{0} \\
\mathbf{0} \\
+ \\
+ \\
+\end{array}$ & $\begin{array}{c}++ \\
0 \\
0 \\
0 \\
0 \\
0 \\
0 \\
0 \\
0 \\
++ \\
0\end{array}$ \\
\hline
\end{tabular}

$0=$ No macroscopic lesions

$+=$ Very slight infection

$++=$ More pronounced infection

$++t=$ Heavy infection 
TABLE IV

Treatment of guinea pigs with streptomycin 2100 units and subtilin $22 \mathrm{mg} . /$ day (three injections) for a period of six weeks

\begin{tabular}{c|c|c|c||c|c|c|c}
\hline \hline Animal & Liver & Lungs & Spleen & Animal & Liver & Lungs & Spleen \\
\hline A1 & 0 & 0 & 0 & B10 & + & 0 & 0 \\
A2 & 0 & 0 & 0 & B11 & 0 & 0 & 0 \\
A3 & 0 & 0 & 0 & C1 & 0 & 0 & 0 \\
A4 & 0 & 0 & 0 & C2 & 0 & 0 & 0 \\
B1 & 0 & 0 & 0 & C3 & 0 & 0 & 0 \\
B2 & 0 & 0 & 0 & C4 & 0 & 0 & 0 \\
B3 & 0 & 0 & 0 & C5 & 0 & 0 & 0 \\
B4 & 0 & 0 & + & C6 & 0 & + & 0 \\
B5 & 0 & 0 & 0 & C7 & 0 & 0 & 0 \\
B6 & 0 & 0 & 0 & C8 & 0 & 0 & 0 \\
B7 & 0 & 0 & 0 & C9 & 0 & 0 & 0 \\
B8 & + & 0 & 0 & C10 & 0 & 0 & 0 \\
B9 & 0 & 0 & 0 & C11 & 0 & + & ++ \\
\hline
\end{tabular}

$0=$ No macroscopic lesions

$t=$ Very slight infection

$++=$ More pronounced infection

$+t+=$ Heavy infection

latter group, five were macroscopically negative. The remaining six exhibited very light infections indicating a pronounced suppressive effect.

Animals Treated with a Mixture of Streptomycin and Subtilin. In this series the animals were treated with both antibiotics. In the earlier experiments the antibiotics were injected separately. In the later experiments it was found that the two antibiotics could be mixed and given in one injection. The results are reported in Table IV. It may be seen that the animals responded excellently to such treatment. Of a total of 26 animals, 21 were macroscopically negative; the remaining five animals exhibited extremely light infections.

\section{DISCUSSION}

Subtilin is not a uniform compound but contains a fraction that is insoluble in serum. The removal of this insoluble fraction gives a product that is soluble in serum in all proportions.

It is felt that emphasis should be placed on the results reported in Table III. They indicate that subtilin might well be used alone for the treatment of tuberculosis. It is seen that the animals treated with a good lot of subtilin responded favorably to treatment and that no toxic manifestations were evident despite the massive doses administered. The low toxicity of subtilin in vivo is in keeping with its results in vitro where it was found that the antibiotic was approximately 20 times more toxic to Micrococcus pyogenes var. aureus than to living embryonic chick heart tissue fragments (7).

A number of subtilin samples, prepared and purified at the Western Regional Research Laboratory, United States Department of Agriculture, have been tested for their tuberculostatic potencies. In view of the known impurity of the antibiotic, the samples showed great variation in their action on the tubercle bacillus. However, subtilin prepared and purified by a method which would give consistently good results might well be used in the treatment of tuberculosis.

Another point which we should like to stress is that the antibiotic may be combined with streptomycin in the chemotherapy of tuberculosis, thereby decreasing the dosage of the latter. By so doing, toxic manifestations of streptomycin may be considerably reduced or perhaps eliminated completely.

\section{ACKNOWLEDGMENT}

The authors wish to express their kindness to Mr. Michael Ordanik for technical assistance during the progress of this work.

\section{BIBLIOGRAPHY}

1. Dimick, K. P., Alderton, G., Lewis, J. C., Lightbody, H. D., and Fevold, H. L., Purification and some properties of subtilin. Arch. Biochem., 1947, 15, 1.

2. Salle, A. J., and Jann, Gregory J., Subtilin-an antibiotic produced by Bacillus subtilis. I. Action on various organisms. Proc. Soc. Exper. Biol. \& Med., 1945, 60, 60.

3. Salle, A. J., and Jann, Gregory J., Subtilin-antibiotic produced by Bacillus subtilis. III. Effect on Type III pneumococcus in mice. Proc. Soc. Exper. Biol. \& Med., 1946, 62, 40.

4. Salle, A. J., and Jann, Gregory J., Subtilin-antibiotic produced by Bacillus subtilis. V. Effect on Streptococcus pyogenes infections in mice. Proc. Soc. Exper. Biol. \& Med., 1946, 63, 519.

5. Salle, A. J., Paper presented at the Conference on Antibiotic Research held at Washington, D. C., on January 31 and February 1, 1947, under the auspices of the Antibiotics Study Section of the National Institutes of Health.

6. Salle, A. J., and Jann, Gregory J., IV. Effect of subtilin on the course of experimental anthrax infections in guinea pigs. Proc. Soc. Exper. Biol. \& Med., 1946, 63, 41.

7. Salle, A. J., and Jann, Gregory J., Subtilin-antibiotic produced by Bacillus subtilis. II. Toxicity of subtilin to living embryonic tissue. Proc. Soc. Exper. Biol. \& Med., 1946, 61, 23. 